\title{
Mitogen-Activated Protein Kinase Kinase 1 (MKK1) Is Negatively Regulated by Threonine Phosphorylation
}

\author{
A. J. ROSSOMANDO, ${ }^{1 *}$ P. DENT, ${ }^{2}$ T. W. STURGILL, ${ }^{2}$ AND D. R. MARSHAK ${ }^{1 *}$ \\ W. M. Keck Structural Biology Laboratory, Beckman Neuroscience Center, Cold Spring Harbor Laboratory, \\ Cold Spring Harbor, New York 11724, ${ }^{1}$ and Department of Pharmacology, \\ University of Virginia, Charlottesville, Virginia $22908^{2}$
}

Received 20 September 1993/Returned for modification 1 November 1993/Accepted 30 November 1993

\begin{abstract}
Mitogen-activated protein kinase kinase 1 (MKK1), a dual-specificity tyrosine/threonine protein kinase, has been shown to be phosphorylated and activated by the raf oncogene product as part of the mitogen-activated protein kinase cascade. Here we report the phosphorylation and inactivation of MKK1 by phosphorylation on threonine 286 and threonine 292 . MKK1 contains a consensus phosphorylation site for p34 ${ }^{\text {cdc } 2}$, a serine/ threonine protein kinase that regulates the cell division cycle, at Thr-286 and a related site at Thr-292. p34 $^{\text {cdc2 }}$ catalyzes the in vitro phosphorylation of MKK1 on both of these threonine residues and inactivates MKK1 enzymatic activity. Both sites are phosphorylated in vivo as well. The data presented in this report provide evidence that MKK1 is negatively regulated by threonine phosphorylation.
\end{abstract}

The regulation of mammalian cell growth is accomplished by the integration of extracellular signals, such as polypeptide growth factors, with intracellular phosphorylation cascades extending from the plasma membrane to the cell nucleus. Recent studies have indicated that mitogen-activated protein (MAP) kinases $(33,41)$, also known as extracellular signalregulated kinases (7), are central to these intracellular signal transduction pathways. Two MAP kinases, p42mapk and $\mathrm{p} 44^{\text {mapk }}$, have been well characterized in many mammalian cell systems $(33,41)$. Both enzymes are phosphorylated on tyrosine and threonine and are activated by a novel protein kinase termed MAP kinase kinase (MKK), also known as MAP kinase/extracellular signal-regulated kinase (MEK) kinase (9, $15,29,34,37)$. The activity of MKK is specific for the regulatory residues, threonine 183 and tyrosine 185 , in $\mathrm{p} 42^{\text {mapk }}$ (32), suggesting that MKK is a key regulator of MAP kinases in the cell.

The regulation of the MKK/MAP kinase pathway is evolving as a network of crosstalking protein kinases and phosphatases that exert both positive and negative signals. For example, the cellular proto-oncogene product, $\mathrm{c}-\mathrm{Raf}-1$, catalyzes the phosphorylation and activation of $\operatorname{MKK}(10,11,23)$. Furthermore, the effects of other upstream protein kinases on MKK activity are also becoming apparent. Several groups have demonstrated a link between the MKK pathway and cyclic AMPdependent protein kinase $(3,8,17,39,43)$. The latter protein kinase is thought to negatively regulate the protein kinase activity of c-Raf-1 (43), thus preventing further activation of the MKK/MAP kinase pathway.

In addition to upstream negative regulation by protein phosphorylation, negative control of the MKK pathway also occurs at the MAP kinase level by dephosphorylation. A MAP kinase-specific phosphatase that specifically removes both types of regulatory phosphorylation has been documented (4). MKK may also be subject to negative regulation by phosphatase action; treatment of active MKK with protein phosphatase $2 \mathrm{~A}$ results in dephosphorylation and inactivation of

${ }^{*}$ Corresponding authors. Phone (D. R. Marshak): (516) 367-8427. Fax (D. R. Marshak): (516) 367-8873. Present address (A. J. Rossomando): Miles Pharmaceuticals, 400 Morgan Ln., West Haven, CT 06516. protein kinase activity $(9,15,29,34,36)$. Although this method of inactivation has not been documented in vivo, observations suggest that additional phosphorylation(s) of MKK occurs following its initial activation and leads to increased susceptibility to inactivation by phosphatase $2 \mathrm{~A}$ in vitro (1). Taken together, these observations demonstrate that both protein kinases and phosphatases act upon MKK directly or indirectly after its initial phosphorylation and activation to rigorously control the activity of the MKK/MAP kinase pathway.

Recently, two isoforms of MKK, known as MKK1 and MKK2, were identified, and their amino acid sequences were elucidated $(9,31,38,45)$. MKK1 contains a consensus sequence for phosphorylation by $\mathrm{p} 34^{c d c 2}$, a key regulator of the cell division cycle $(5,30)$, at Thr-286, as well as another, related site at Thr-292. Active p34 ${ }^{c d c 2}$ kinase is a proline-directed protein kinase that preferentially catalyzes the phosphorylation of serine or threonine in the sequence $\mathrm{S} / \mathrm{TP}(\mathrm{X})_{n} \mathrm{Z}$, where $n=1$ to 3 and $\mathrm{Z}$ is often lysine or arginine (28). Thr-286 and Thr-292 are located within a large proline-rich insert in MKK1, near the substrate binding domain (between domains IX and $\mathrm{X}$ ), suggesting a possible regulatory role for these potential phosphorylation sites. Although MKK1 and MKK2 are highly homologous, several important differences exist between these enzymes: the amino acid at position 286 in MKK1 is valine in MKK2, and the residue at position 292 in MKK1 is proline in MKK2. On the basis of these observations, we evaluated the potential regulation of mammalian MKK1 by $\mathrm{p} 34^{c d c 2}$ by testing its ability to phosphorylate MKK1 and to modify its enzymatic activity.

\section{MATERIALS AND METHODS}

Cell culture. HeLa cells were grown in suspension as previously described (27). HeLa cells were $\mathbf{M}$ phase arrested by treating $5 \times 10^{5}$ cells per ml with $0.1 \mu \mathrm{g}$ of nocodazole (Sigma, St. Louis, Mo.) per $\mathrm{ml}$ for $20 \mathrm{~h}$ prior to lysis (27).

Recombinant and wild-type proteins. Baculovirus-expressed MKK1 and MKK2, both containing a 12-amino-acid histidine tag at the amino terminus, were activated by coexpression in Sf 9 insect cells with v-Raf or left unactivated. Both proteins were purified from the $\mathrm{Sf} 9$ insect cell lysate by batch adsorption to metal-chelating Sepharose (Pharmacia, Piscataway, N.J.) 
loaded with $\mathrm{Ni}^{2+}$. The resin was washed once with homogenization buffer ( $25 \mathrm{mM}$ Tris- $\mathrm{HCl}$ [pH 7.9], $2 \mathrm{mM}$ imidazole $\mathrm{HCl}$ [pH 7.9], $10 \%$ glycerol, $1 \%$ Nonidet P-40 [NP-40], $500 \mathrm{mM}$ $\mathrm{NaCl}, 25 \mathrm{mM} \mathrm{NaF}, 1 \mathrm{mM} \mathrm{Na} \mathrm{VO}_{4}, 1 \mathrm{mM} \mathrm{P} \mathrm{O}_{7}, 1 \mathrm{mM}$ benzamidine, $1 \mathrm{mM}$ phenylmethylsulfonyl fluoride [PMSF], $0.1 \% \beta$-mercaptoethanol), once with homogenization buffer without NP-40 and $\mathrm{NaCl}$, and once with the latter buffer containing $20 \mathrm{mM}$ imidazole ( $\mathrm{pH}$ 7.9). The MKK protein was eluted from the resin with $250 \mathrm{mM}$ imidazole, diluted approximately 10 -fold with $\mathrm{H}_{2} \mathrm{O}$, and applied to a Mono Q (Pharmacia) anionic-exchange column equilibrated with homogenization buffer without $\mathrm{NP}-40$ and $\mathrm{NaCl}$. A linear $\mathrm{NaCl}$ gradient (from 0 to $500 \mathrm{mM}$ ) was used to elute MKK from the resin. MKK eluted at 125 to $150 \mathrm{mM} \mathrm{NaCl}$ and was stored at $-20^{\circ} \mathrm{C}$ with $50 \%$ glycerol. Both the MKK1 and the MKK2 preparations were determined to be nearly homogenous by silver staining and free of contaminating $\mathrm{v}$-Raf by immunoblotting with an anti-Raf antibody (data not shown). However, two MKK2 proteins were identified by silver staining and by immunoblotting, suggesting that the MKK2 preparation contained a proteolytic MKK2 fragment.

Mitotic p34 $4^{c d c 2}$ kinase was purified to near homogeneity from HeLa cells as previously reported $(2,27)$ and as described briefly below. Cultured HeLa cells ( 32 liters) were treated with nocodazole as described above to effect arrest in $\mathbf{M}$ phase. The DNA content of the $G_{2} / M$ phase-blocked cells was confirmed by fluorescence-activated cell sorter analysis. p34 ${ }^{\text {cdc2 }}$ kinase activity was monitored throughout the purification with a synthetic peptide as a substrate (H-ADAQHATPPKKKRKV EDPKDF-OH) in kinase assays as described previously $(2,27)$. The cells were harvested by centrifugation and lysed in $100 \mathrm{ml}$ of hypotonic buffer (10 mM sodium phosphate [pH 7.0], 10 $\mathrm{mM} \mathrm{NaF}, 5 \mathrm{mM} \mathrm{MgCl}_{2}, 1 \mathrm{mM}$ EDTA, $10 \mathrm{mM} \beta$-glycerol phosphate) by use of a Dounce homogenizer in the presence of protease inhibitors. A $50 \%\left(\mathrm{NH}_{4}\right)_{2} \mathrm{SO}_{4}$ precipitate was pelleted and resuspended in $100 \mathrm{ml}$ of buffer A $(50 \mathrm{mM}$ Tris- $\mathrm{HCl}$ [pH 7.0], $5 \mathrm{mM} \mathrm{MgCl}$, $1 \mathrm{mM}$ EDTA, $1 \mathrm{mM}$ dithiothreitol, 10 $\mathrm{mM} \beta$-glycerol phosphate). This solution was dialyzed against 1.5 liters of buffer A overnight at $4^{\circ} \mathrm{C}$. On the following day, the conductivity was adjusted to that of buffer B (same as buffer A but containing $80 \mathrm{mM} \mathrm{NaCl}$ ). The sample was then applied to a DE52 (Whatman) column equilibrated with buffer $B$. The unbound protein fraction was dialyzed overnight against 1 liter of buffer 2 (50 mM $N$-2-hydroxyethylpiperazine- $N^{\prime}$-2-ethanesulfonic acid [HEPES] [pH 7.0], $5 \mathrm{mM} \mathrm{MgCl} 2,1 \mathrm{mM}$ EDTA, $1 \mathrm{mM}$ dithiothreitol, $100 \mathrm{mM} \mathrm{NaCl}, 10 \%$ glycerol). Following dialysis, the sample was applied to an S-Sepharose (Pharmacia) column equilibrated with buffer 2 , and the protein was eluted with a linear $\mathrm{NaCl}$ gradient (from 100 to $500 \mathrm{mM}$ ). Fractions containing active p34 $4^{c d c 2}$ kinase were pooled and diluted with buffer $A$ until the conductivity reached that of buffer B. This solution was applied to a 5-ml casein-Sepharose column ( $5 \mathrm{mg}$ of casein per $\mathrm{ml}$ ) equilibrated with buffer B. A linear $\mathrm{NaCl}$ gradient (from 80 to $500 \mathrm{mM}$ ) was used to elute p34 ${ }^{c d c 2}$ kinase. The kinase activity peak was identified, and fractions were pooled and adjusted to $80 \mathrm{mM} \mathrm{NaCl}$ with buffer A. Q-Sepharose (Pharmacia) chromatography, with a linear $\mathrm{NaCl}$ gradient (from 80 to $500 \mathrm{mM}$ ), was used to further fractionate the protein sample. Again, p34 ${ }^{\text {cdc2 }}$ kinase was identified, and fractions were pooled. The pooled activity was concentrated with a 10,000-molecular-weight cutoff (Centricon; Amicon, Danvers, Mass.), and the concentrated proteins were suspended with glycerol to $50 \%$. The p34 $4^{c d c 2}$ and cyclin proteins were found to be nearly homogenous by silver staining, and $\mathrm{p} 34^{c d c 2}$ kinase activity towards the substrate peptide was linear over $30 \mathrm{~min}$ at $30^{\circ} \mathrm{C}$. Both the $K_{m}$ and the $V_{\max }$ of this preparation were previously described $(2,27)$. The enzyme was stored at $-20^{\circ} \mathrm{C}$ until needed. p34 $4^{c d c 2}$ kinase in this study consists of the human $34-\mathrm{kDa}$ catalytic subunit and mitotic p62 cyclin $(2,27)$.

Kinase-defective MAP kinase (K52R), containing a lysineto-arginine substitution at position 52 , was previously described (25).

Protein kinase assays. Each $40 \mu \mathrm{l}$ of the kinase mixture (50 $\mu \mathrm{M}$ ATP, $20 \mathrm{mM} \mathrm{MgSO}_{4}, 1 \mathrm{mM}$ DTT, $20 \mathrm{mM}$ HEPES [pH 7.5], 5,000 cpm of $\left[\gamma^{32} \mathrm{P}\right] \mathrm{ATP}$ per pmol) contained one or more of the following: $100 \mathrm{ng}$ of $\mathrm{p} 34^{c^{d c 2}}, 1 \mu \mathrm{g}$ of MKK1, $2 \mu \mathrm{g}$ of K52R, or $4 \mu \mathrm{g}$ of histone H1 (Sigma). MKK1 and p34 ${ }^{\text {cdc2 }}$ were incubated together at $30^{\circ} \mathrm{C}$ for $12 \mathrm{~min}$ prior to the addition of K52R. All reaction mixtures were then incubated at $30^{\circ} \mathrm{C}$ for $12 \mathrm{~min}$, the reactions were stopped by the addition of sodium dodecyl sulfate (SDS) sample buffer (24), and the mixtures were subjected to electrophoresis on a $10 \%(\mathrm{wt} / \mathrm{vol})$ polyacrylamide gel in the presence of SDS. The gel was stained with Coomassie blue and dried, and the labeled proteins were visualized by autoradiography for $3.5 \mathrm{~h}$ at $-70^{\circ} \mathrm{C}$.

Peptide synthesis. The MKK1 peptide, corresponding to murine MKK1 residues 277 through 300, was synthesized on an ABI (Foster City, Calif.) $430 \mathrm{~A}$ peptide synthesizer and purified by reverse-phase high-pressure liquid chromatography (HPLC), and the molecular weight was verified by mass spectral analysis on a mass spectrometer from Bio-Ion Inc. (Uppsala, Sweden).

Phosphopeptide mapping and sequencing. High-voltage electrophoresis-thin-layer chromatography (HVE/TLC) was performed as previously described (12). In all cases, electrophoresis was along the horizontal axis and ascending hydrophobic chromatography was along the vertical axis with respect to the origin. Each phosphorylated peptide was scraped off the cellulose plate, eluted with $\mathrm{pH} 1.9$ electrophoresis buffer (12), covalently attached to an aryl amine-derivatized membrane (Millipore, Bedford, Mass.), and subjected to repetitive cycles of Edman degradation as described previously $(12,35)$.

For phosphopeptide sequencing, the MKK1 peptide (350 $\mu \mathrm{M})$ was phosphorylated by $\mathrm{p} 34^{\text {cdd } 2}$ under the kinase assay conditions described above and purified from the kinase reagents by reverse-phase HPLC. The phosphorylated peptide was left undigested or digested for $4 \mathrm{~h}$ with $10 \mu \mathrm{g}$ of trypsin (Boehringer Mannheim Biochemicals, Indianapolis, Ind.) at $37^{\circ} \mathrm{C}$ and then incubated with an additional $10 \mu \mathrm{g}$ of trypsin overnight at the same temperature. Both samples were subjected to HVE/TLC and repetitive Edman sequencing.

For phosphopeptide map comparisons, each sample was phosphorylated as described above or isolated from ${ }^{32} \mathrm{P}$ labeled HeLa cells by immunoprecipitation, digested with 10 $\mu \mathrm{g}$ of thermolysin (Boehringer) in $50 \mathrm{mM}$ ammonium bicarbonate, incubated at $37^{\circ} \mathrm{C}$ for $4 \mathrm{~h}$, and subjected to HVE/TLC.

Immunoblotting and immunoprecipitation. An MKK1 peptide antibody (R1) was generated in rabbits against the synthetic peptide described above. Affinity-purified antibodies were isolated on an MKK1 peptide column and shown to be specific for MKK1 by immunoblotting and immunoprecipitating baculovirus-expressed MKK1 (data not shown). Antiserum specific for $\mathrm{p} 34^{c d c 2}(\mathrm{G} 6)$ was generated in rabbits against the peptide carboxy terminus (11) of mammalian p34 $4^{\text {cdc2 }}$ kinase. An STE7 antipeptide antibody was provided by Steve Pelech, University of British Columbia. This antibody was generated against a peptide sequence (H-FVGTSTYMSPERI-Cys) from yeast STE7 and cross-reacts with mammalian MKK1 and MKK2 at the sequence H-FVGTRSYMSPERL-OH $(19,44)$.

For direct immunoblotting of HeLa total cell lysate, approximately $10^{6}$ asynchronously growing HeLa cells were lysed with 


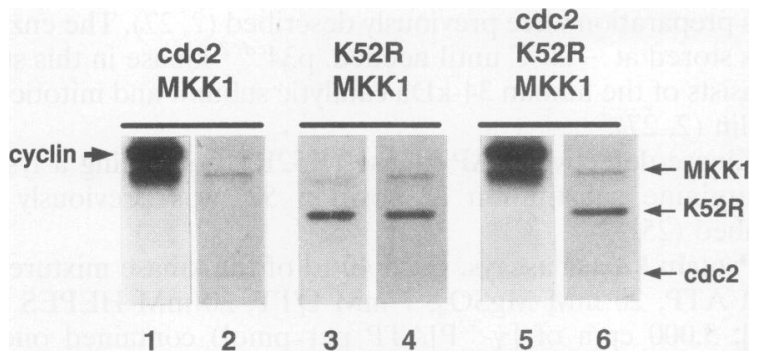

FIG. 1. Phosphorylation and inactivation of recombinant MKK1 by p34 $4^{c d c 2}$. Lanes: 1 and 2, p34 $4^{c d c 2}$ and MKK1; 3 and 4, K52R and MKK1; 5 and $6, \mathrm{p} 34^{c d c 2}, \mathrm{~K} 52 \mathrm{R}$, and MKK1. The proteins identified in lanes 2, 4 , and 6 were Coomassie blue stained, and the labeled proteins in lanes 1,3 , and 5 were visualized by autoradiography. The migration of each protein is indicated to the right. Cyclin is labeled on the left.

SDS sample buffer (24). For all precipitations, the cells were lysed in NP-40 lysis buffer (50 mM Tris [pH 7.4], $150 \mathrm{mM}$ $\mathrm{NaCl}, 1 \% \mathrm{NP}-40,10 \mathrm{mM}$ EDTA, $10 \%$ glycerol, $1 \mathrm{mM}$ $\mathrm{Na}_{3} \mathrm{VO}_{4}, 40 \mathrm{mM} \mathrm{NaF}, 100 \mu \mathrm{g}$ of PMSF per ml, $1 \mu \mathrm{g}$ of leupeptin per $\mathrm{ml}, 50 \mu \mathrm{g}$ of soybean trypsin inhibitor per $\mathrm{ml}, 100$ $\mu \mathrm{g}$ of tolylsulfonyl phenylalanyl chloromethyl ketone [TPCK] per ml, $4 \mathrm{mM} p$-nitrophenyl phosphate). Asynchronously growing HeLa cells $\left(10^{5}\right)$ were metabolically labeled with ${ }^{32} \mathrm{P}_{\mathrm{i}}$ (NEN, Boston, Mass.) for $2 \mathrm{~h}$ (see below), and then MKK was immunoprecipitated with $10 \mu \mathrm{g}$ of R1 antibody. SDS sample buffer was used to elute immunoprecipitated MKK from the antibody-protein A agarose (Pierce, Rockford, Ill.) complex. The HeLa cell lysate and immunoprecipitated proteins were subjected to electrophoresis on a $10 \%(\mathrm{wt} / \mathrm{vol})$ polyacrylamide gel containing SDS and transferred to nitrocellulose (Schleicher \& Schuell, Keene, N.H.). The filter was exposed to film with an intensifying screen for $3.5 \mathrm{~h}$ at $-70^{\circ} \mathrm{C}$. Following film exposure, $\mathrm{R} 1$ was used to immunoblot the proteins on the filter. Detection of R1 binding to MKK was accomplished with a horseradish peroxidase-conjugated anti-rabbit IgG antibody and chemiluminesence (ECL; Amersham, Arlington Heights, Ill.). The filter was exposed to film for $1 \mathrm{~min}$ at room temperature. The same exposure prior to immunoblotting did not reveal any ${ }^{32} \mathrm{P}$-labeled proteins.

Rat MKK1 and rat MKK2 (100 ng each) were subjected to SDS-polyacrylamide gel electrophoresis (PAGE) as described above, transferred to nitrocellulose, probed with STE7 (1:1,000 dilution) or R1 (10 $\mu \mathrm{g})$ antibody, and detected by use of ECL.

Precipitations of $\mathrm{p} 34^{c d c 2}$ were performed as described above, except that $8 \mu \mathrm{l}$ of G6 was used per p34 $4^{\text {cdc } 2}$ precipitation. When necessary, all polyacrylamide gels were stained with Coomassie blue to verify the protein levels loaded per lane prior to exposure to film.

Cell labeling. Asynchronously growing HeLa cells were washed several times in Dulbecco minimal essential medium without phosphate (GIBCO, Grand Island, N.Y.), suspended at $10^{7}$ cells per $\mathrm{ml}$ in the same medium, and incubated at $37^{\circ} \mathrm{C}$ for $1 \mathrm{~h}$ prior to labeling. ${ }^{32} \mathrm{P}_{\mathrm{i}}$ was added to a $1-\mathrm{mCi} / \mathrm{ml}$ final concentration and incubated at $37^{\circ} \mathrm{C}$ for $2 \mathrm{~h}$ with constant mixing prior to lysis with NP-40 lysis buffer.

\section{RESULTS}

Phosphorylation of recombinant MKK1 by $\mathrm{p34}^{\text {cdc2 }}$. To determine whether active p34 ${ }^{c d c 2}$ kinase containing both the catalytic and the cyclin subunits phosphorylated MKK1, a baculovirus-expressed and enzymatically active rat fusion protein (MKK1) was used as an in vitro substrate in protein kinase

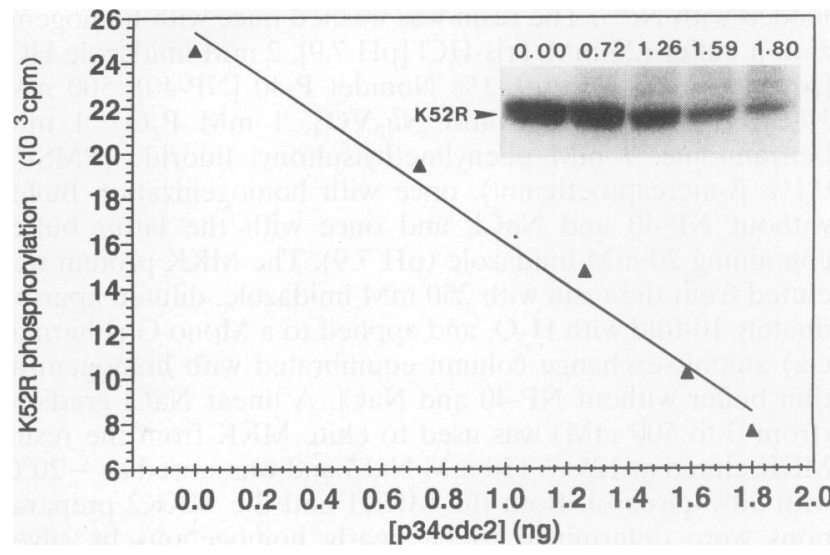

FIG. 2. MKK1 inactivation is dependent upon the concentration of p3 $34^{c d c 2}$ kinase. MKK1 was incubated with various amounts of $\mathrm{p} 34^{c d c 2}$ (from 0 to $1.8 \mathrm{ng}$; top of inset and abscissa) for $12 \mathrm{~min}$ prior to the addition of K52R. Following an additional 12 min of incubation, the reaction mixtures were subjected to SDS-PAGE. K52R was identified by Coomassie blue staining and by autoradiography (inset). Each protein band was excised from the gel, and Cerenkov radiation was measured (ordinate).

assays (Fig. 1). In reaction mixtures containing both MKK1 and $\mathrm{p} 34^{c d c 2}$, MKK1 was detected as a 49-kDa phosphoprotein (lane 1) that comigrated with a Coomassie blue-stained recombinant protein (lane 2). This phosphorylation was not detectable in samples containing p34 $4^{c d c 2}$ alone with $\left[\gamma-{ }^{32} \mathrm{P}\right] \mathrm{ATP}$ and $\mathrm{Mg}$, and in the absence of other protein kinases, MKK1 was weakly autophosphorylated. The stoichiometry of MKK1 phosphorylation by p34 ${ }^{c d c 2}$ was determined to be approximately 1.7 mol of phosphate per mol of MKK1 (data not shown). An additional phosphoprotein of $62 \mathrm{kDa}$ was observed in samples containing p34 ${ }^{c d c 2}$ (lanes 1 and 5); it corresponded to the $\mathrm{p} 34^{c d c 2}$-associated $\mathrm{p} 62$ cyclin that is phosphorylated by $\mathrm{p} 34^{c d c 2}$ $(2,11,27)$.

Inactivation of MKK1 by $\mathbf{p 3}^{\text {cdc2 }}$. To evaluate the effects of $\mathrm{p} 34^{c d c 2}$ on MKK1 function, it was necessary to include a specific substrate for MKK, namely, p42 $2^{\text {mapk}}$. However, wildtype $\mathrm{p} 42^{\text {mapk }}$ has been shown to be autophosphorylated on tyrosine $(36,46)$. To avoid any interference by autophosphorylation, a mutant of $\mathrm{p} 42^{\text {mapk }}(\mathrm{K} 52 \mathrm{R})$ that is defective for protein kinase activity $(25,34)$ was used as a substrate to measure MKK1 activity (Fig. 1, lane 3). When $\mathrm{p} 34^{c d c 2}$ was preincubated with MKK1 prior to the addition of $\mathrm{K} 52 \mathrm{R}$, phosphorylation of K52R failed to occur (lane 5), even though the amounts of K52R and MKK1 present in the reaction (lane 6) were equal to those present in the MKK1-K52R control (lane 4). This result suggested that MKK1 phosphorylation by p34 ${ }^{c d c 2}$ inactivated the enzyme. To further test this conclusion and to exclude other explanations, several additional experiments were performed: (i) p34 ${ }^{c d c 2}$ did not phosphorylate K52R; (ii) when p34 ${ }^{\text {cdc2 }}$ was incubated alone, only p62 cyclin B became phosphorylated; and (iii), as expected, K52R was not autophosphorylated. Also, since no v-Raf was identified in our preparations (see Materials and Methods), the observed result cannot be attributed to an interaction between $\mathrm{p} 34^{c d c 2}$ and $v$-Raf.

Further control experiments demonstrated that MKK1 was enzymatically inactivated by $\mathrm{p} 34^{c d c 2}$ kinase and that the inactivation was not an artifact attributable to contaminating agents. When the p34 $4^{c d c 2}$ concentration in the inactivation assay was varied, the degree to which $\mathrm{K} 52 \mathrm{R}$ phosphorylation 


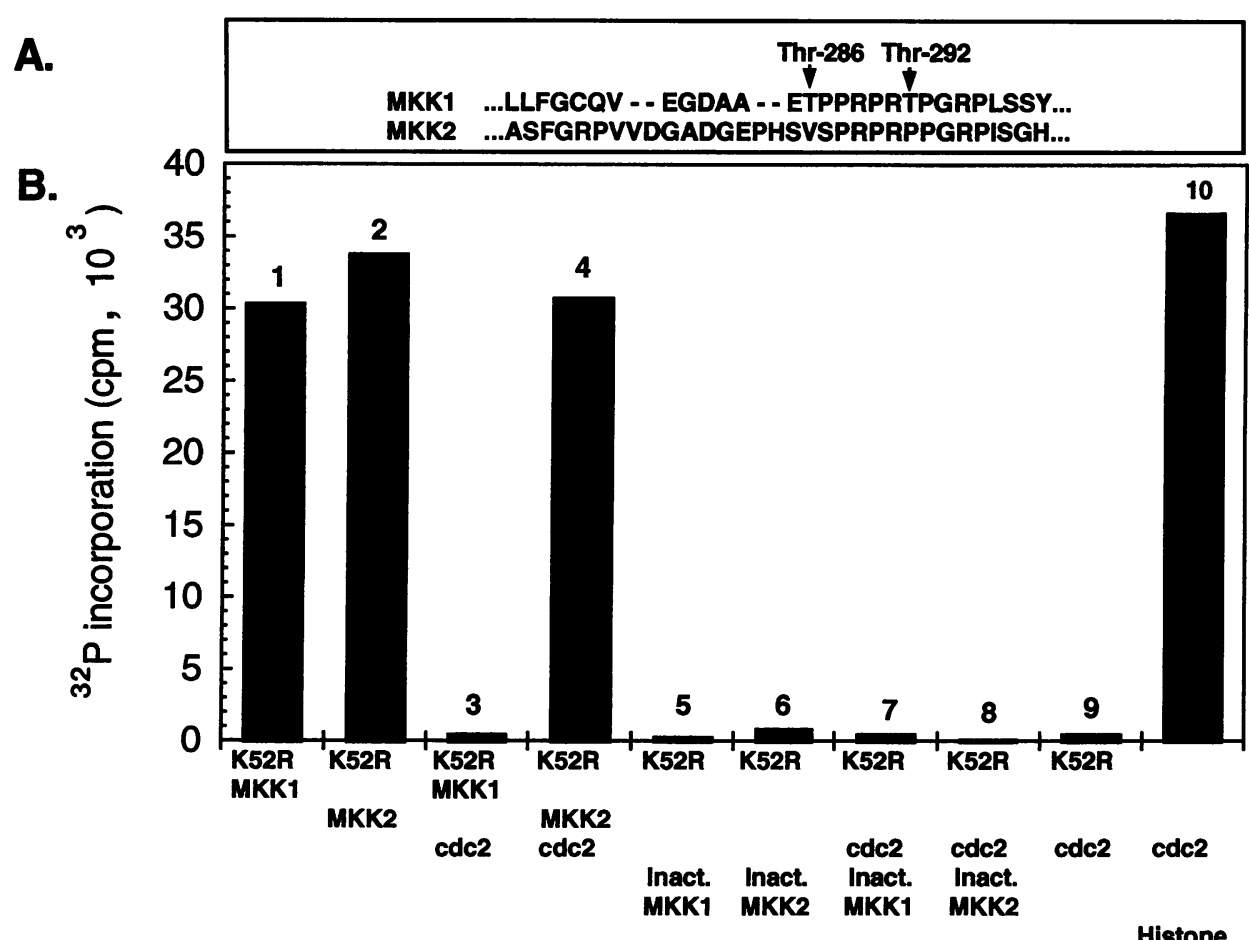

FIG. 3. $\mathrm{p} 34^{c d c 2}$ does not catalyze the phosphorylation or inactivation of MKK2. (A) Comparison of the rat MKK1 and rat MKK2 amino acid sequences between kinase domains IX and X. Thr-286 and Thr-292 are indicated by arrows above the sequence. Dashes indicate gaps inserted to properly align the sequences. (B) Graphic representation of the K52R and histone H1 kinase assays. Following incubation of the assay components (listed below each bar on the abscissa), the kinase assays (see Materials and Methods) were stopped with SDS sample buffer, and samples were subjected to electrophoresis through a $10 \%$ polyacrylamide gel. K52R and histone H1 were identified by Coomassie blue staining and autoradiography. The proteins were excised from the gel, and Cerenkov radiation was counted. This is a representative result of three separate assays. The ordinate shows counts incorporated into $\mathrm{K} 52 \mathrm{R}$ or histone $\mathrm{H} 1$ per minute $\left(10^{3}\right)$. All protein components are described in the text. Inact., inactivated.

was reduced was linearly dependent upon the amount of p34 $4^{c d c 2}$ present (Fig. 2). Furthermore, heat inactivation of p34 ${ }^{c d c 2}$ prior to its addition to the kinase reaction failed to inhibit the phosphorylation of K52R by MKK1. This result argues that the observed inactivation of MKK1 is enzymatic and is not caused by a contaminant within the $\mathrm{p} 34^{\text {cdc2 }}$ preparation.

Small amounts of CDC25, a tyrosine/threonine phosphatase, have been documented to be complexed with p34 ${ }^{c d c 2}$-cyclin (14); therefore, this or other phosphatases could be responsible for the observed MKK1 inactivation. To address this issue, various phosphatase inhibitors were included in the MKK1 inactivation assay. The addition of the phosphatase inhibitors 1 $\mathrm{mM}$ sodium vanadate, $4 \mathrm{mM} p$-nitrophenyl phosphate, and 1 $\mu \mathrm{M}$ okadaic acid to the reaction mixtures failed to prevent MKK1 inactivation (data not shown). These results demonstrate that the inactivation of MKK1 is not attributable to the removal of the activating phosphate by a contaminating phosphatase within the $\mathrm{p} 34^{c c_{c 2}}$ preparation.

p34 ${ }^{\text {cdc2 }}$ does not inactivate MKK2. Recently, the cloning and sequencing of rat MKK2 were reported (44). MKK1 and MKK2 are highly conserved throughout most of their amino acid sequences but diverge significantly near the amino terminus and between kinase domains IX and X (Fig. 3A), the region containing Thr-286 and Thr-292 in MKK1. Since both threonines are absent in MKK2 and both represent potential p34 ${ }^{c d c 2}$ phosphorylation sites on MKK1, we used baculovirusexpressed MKK2 (preactivated with v-Raf and purified) containing a 12-residue histidine tag at the amino terminus to evaluate the ability of $\mathrm{p} 34^{c d c 2}$ to catalyze the in vitro phosphorylation and inactivation of MKK2. Representative kinase assays with $\mathrm{K} 52 \mathrm{R}$ or histone $\mathrm{H} 1$ as a substrate are graphically presented in Fig. 3B. Both MKK1 and MKK2 catalyzed the phosphorylation of K52R (bars 1 and 2). MKK1 (bar 3) but not MKK2 (bar 4) was inactivated by p34 ${ }^{\text {cdc2 }}$ kinase. In agreement with this result, $\mathrm{p} 34^{c d c 2}$ did not catalyze the in vitro phosphorylation of MKK2 (data not shown). As expected, control experiments demonstrated that enzymatically inactivated MKK1 and MKK2 did not catalyze the phosphorylation of K52R (bars 5 and 6) and that the p34 ${ }^{c d c 2}$ preparation did not catalyze the enzymatic activation of MKK1 and MKK2 (bars 7 and 8 , respectively). The $\mathrm{p} 34^{c d c 2}$ preparation did not phosphorylate K52R (bar 9) but did catalyze the phosphorylation of histone H1 (bar 10). Since $\mathrm{p} 34^{\text {cdc2 }}$ did not catalyze the phosphorylation or inactivation of $\mathrm{MKK} 2$, these data indicate that MKK1 inactivation is catalyzed by $\mathrm{p} 34^{c d c 2}$ and further demonstrate that MKK1 inactivation is not the result of a contaminating phosphatase within the $\mathrm{p} 34^{c d c 2}$ preparation.

Phosphorylation of a synthetic peptide that contains Thr286 and Thr-292 by p34 $^{\text {cdc2 }}$. To determine whether Thr-286 was phosphorylated by $\mathrm{p} 34^{c d c 2}$, a synthetic peptide corresponding to MKK1 residues 277 through $300(1,9,38,45)$ was used as a substrate in kinase assays. Phosphorylation of the peptide was linear with substrate concentration. The $K_{m}$ for MKK1 peptide phosphorylation by $\mathrm{p} 34^{c d c 2}$ was determined to be approximately $125 \mu \mathrm{M}$; the $V_{\max }$ was $1,388 \mathrm{nmol} / \mathrm{min} / \mathrm{mg}$ (data not shown).

Phosphoamino acid analysis was performed following the 
A.

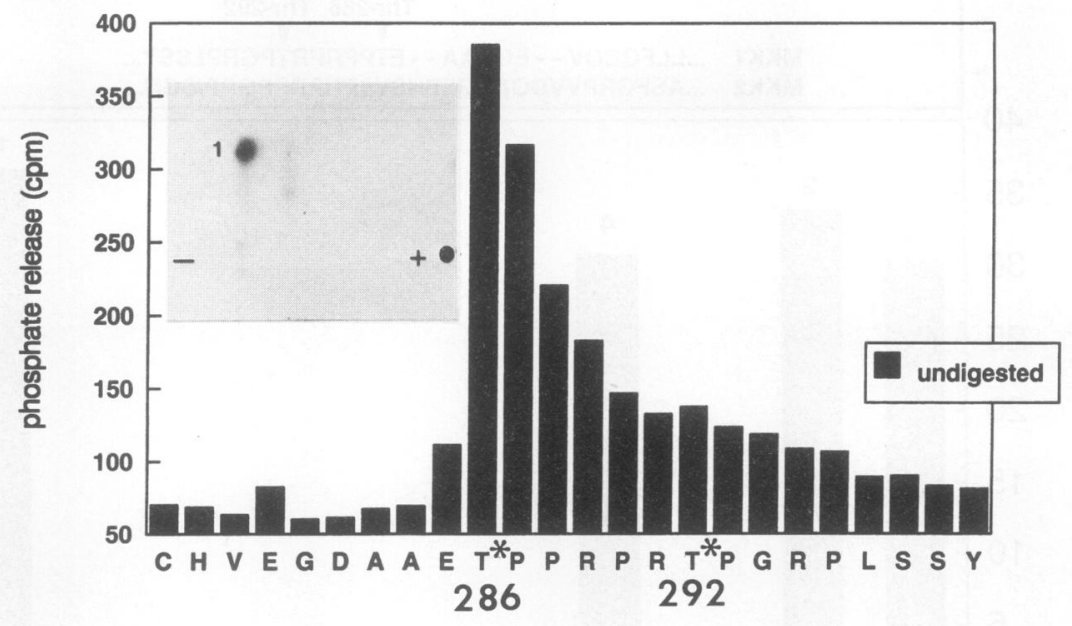

B.

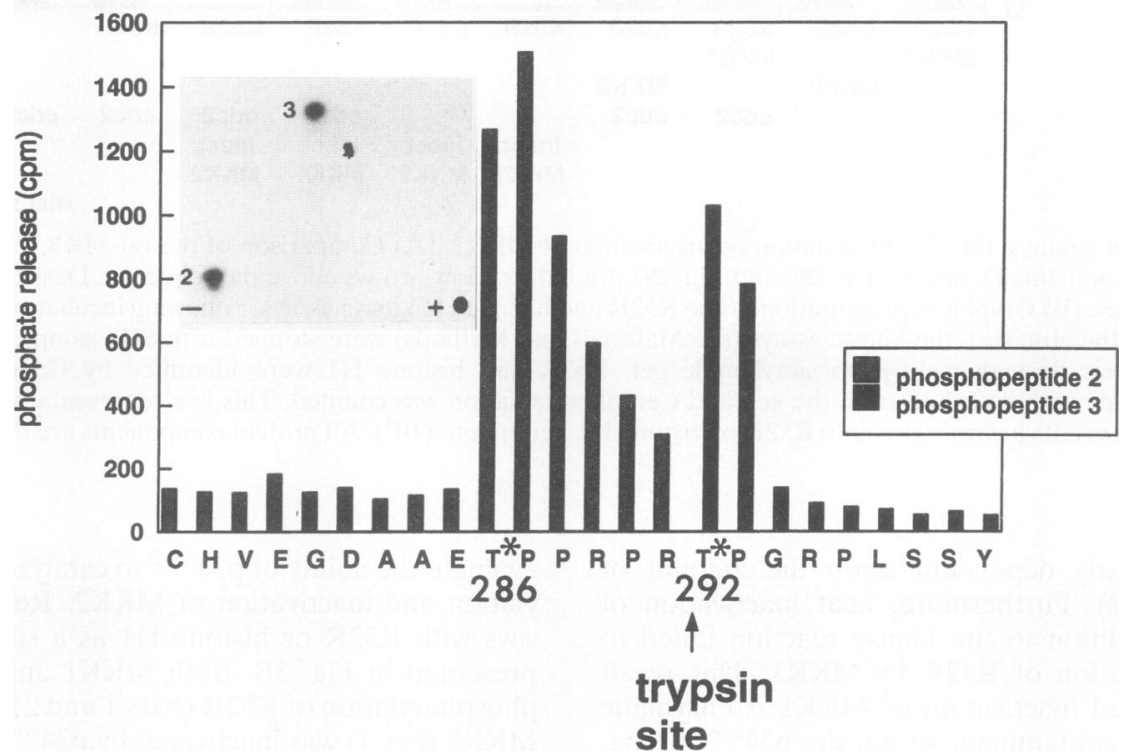

FIG. 4. Identification of $\mathrm{p} 34^{c d c 2}$ phosphorylation sites within undigested (A) and trypsin-treated (B) synthetic MKK1 peptide by repetitive Edman degradation on an ABI 473A protein sequencer. The insets in panels A and B are two-dimensional phosphopeptide maps of undigested and trypsin-generated phosphopeptides, respectively. Origins are represented by $\mathbf{O}$, and the electrophoretic dimensions are indicated by + and - . The hydrophobic chromatography dimension extends upwards from the origin. Thr-286 and Thr-292 are labeled in each panel by an asterisk, and the trypsin cleavage site is marked by an arrow in panel B. Abscissa, corresponding peptide residue. Ordinate, counts per minute released following each cleavage cycle. The "blob" just below and to the right of spot 3 represents an artifact of autoradiography.

phosphorylation of the synthetic peptide by $\mathrm{p} 34^{\text {cdd } 2}$, and only phosphothreonine was detected (data not shown). To determine the site of phosphorylation, the phosphorylated peptide was subjected to two-dimensional HVE/TLC (Fig. 4A, inset), elution, and repetitive Edman degradation. Phosphate release from the sequencer corresponded to Thr-286 (cycle 10) being the predominant site of threonine phosphorylation by $\mathrm{p} 34^{\text {cdc } 2}$ (Fig. 4A). However, the phosphate level did not return to the baseline, suggesting that Thr-292 was also phosphorylated. To test this hypothesis, the phosphorylated peptide was proteolytically cleaved with trypsin and subjected to HVE/TLC (Fig. 4B, inset). Two novel phosphopeptides were identified and subjected to sequence analysis for the release of ${ }^{32} \mathrm{P}$-labeled residues. Phosphopeptide 2 contained phosphorylated Thr286, and phosphopeptide 3 contained phosphorylated Thr-292
(Fig. 4B). The amino acid sequence of phosphopeptide 3 was confirmed by repetitive Edman degradation and an analysis of amino acid residues at each cycle independently of the phosphopeptide sequence (data not shown).

Phosphopeptide mapping of MKK1. p34 $4^{c d c^{2}}$-phosphorylated MKK1 (Fig. 1, lane 1) was digested with thermolysin and subjected to two-dimensional phosphopeptide mapping (Fig. 5A). Two predominant phosphopeptides, one major and one minor (labeled $\alpha$ and $\beta$, respectively), were observed. Several additional minor phosphopeptides, possibly reflecting incomplete digestion, were also identified.

Phosphopeptide mapping was also performed on the thermolysin-treated synthetic MKK1 peptide phosphorylated by p34 $4^{\text {cd }} 2$ (Fig. 5B). Two phosphopeptides (labeled 1 and 2) were identified. Both migrated, with respect to the origin, in posi- 


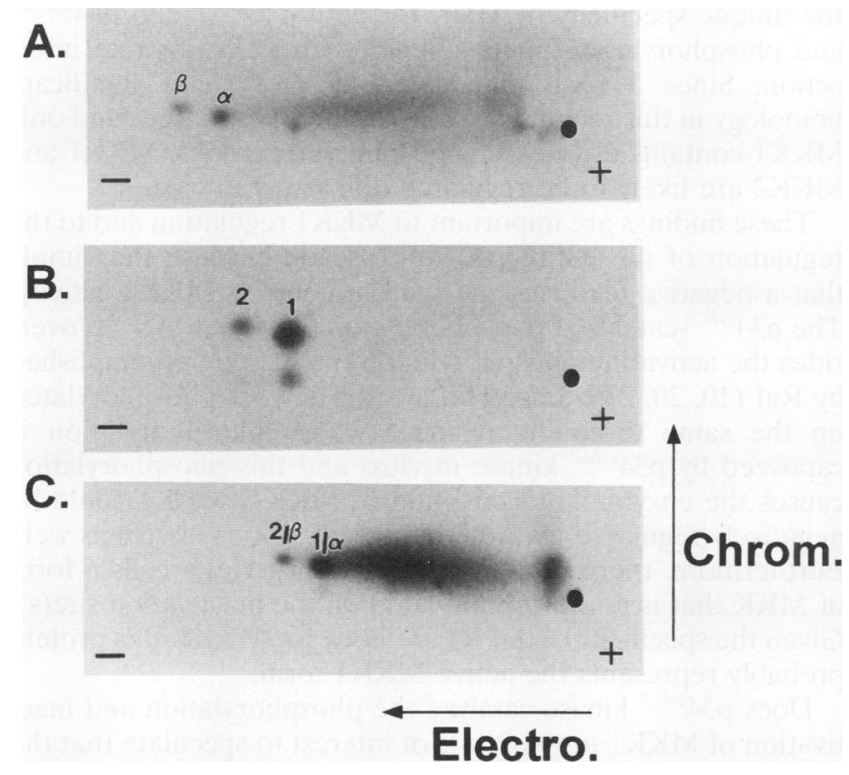

FIG. 5. Mapping of MKK1 phosphopeptides. (A) Recombinant MKK1. (B) Synthetic MKK1 peptide. (C) Mixture of panels A and B. , origin. The electrophoretic (Electro.) dimensions are indicated by + and -, and the ascending chromatography (Chrom.) dimension is indicated by the arrow to the right of panels $B$ and $C$ ).

tions similar to those of phosphopeptides $\alpha$ and $\beta$ identified in Fig. 5A. To determine the relationship of phosphopeptides 1 and 2 to phosphopeptides $\alpha$ and $\beta$, samples identical to those in Fig. 5A and B were mixed and subjected to phosphopeptide mapping (Fig. 5C). Phosphopeptides 1 and 2 comigrated with phosphopeptides $\alpha$ and $\beta$, respectively. Thus, MKK1 appears to be phosphorylated by $\mathrm{p} 34^{\text {cdc2 }}$ on the site corresponding to the synthetic MKK1 peptide. Since MKK1 is phosphorylated on both Thr-286 and Thr-292, phosphopeptide $\alpha$ is likely to contain both of these sites phosphorylated, while phosphopeptide $\beta$ may be a singly phosphorylated form.

Identification of MKK in HeLa cell extracts. MKK1-specific antisera were raised in rabbits against the above-mentioned synthetic MKK1 peptide, and the corresponding antibodies were affinity purified for use in identifying MKK1. To determine the antibody specificity, recombinant MKK1 and MKK2 were subjected to SDS-PAGE and immunoblotted with the R1 antibody (Fig. 6). In addition, identical samples were immunoblotted with an antibody to STE7 (see Materials and Methods), a yeast MKK homolog (13). The STE7 antibody reacts with an epitope that is conserved among known MKKs. The STE7 antibody reacted with both MKK1 and MKK2 (left panel), but only MKK1 was detected by the R1 antibody (right panel).

To expand our studies of MKK1 inactivation in vivo, it was necessary to identify and precipitate the protein from cell lysates so that its phosphorylation state could be determined. Therefore, we used the R1 antibody to immunoblot HeLa cell lysates (Fig. 7). R1 reacted with a $45-\mathrm{kDa}$ protein doublet in lysates from HeLa cells growing asynchronously (third lane, arrows). It also immunoprecipitated and immunoblotted similar proteins (second lane) from the same cells labeled with ${ }^{32} \mathbf{P}_{\mathrm{i}}$, and both proteins were phosphorylated (first lane). Thus, at least two MKK1 phosphoproteins or differentially phosphorylated forms exist in the asynchronous HeLa cell population. Furthermore, the protein with the slower SDS gel mobility reproducibly predominated in $M$ phase-blocked HeLa cells

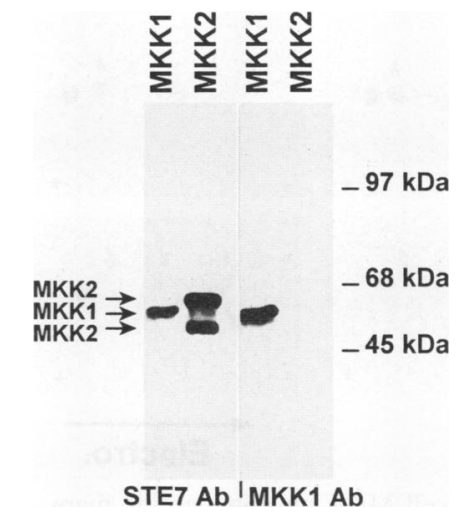

FIG. 6. MKK1 antibody specificity. Two samples each of rat MKK1 and rat MKK2 (100 ng) were subjected to electrophoresis on a $10 \%$ polyacrylamide gel and transferred to nitrocellulose. One set of proteins was immunoblotted with an antibody STE7 (left panel), and one set was immunoblotted with the MKK1 (R1) antibody (right panel). The protein contained in each lane is given above the lane, and MKK1 and MKK2 are indicated to the left by arrows. Molecular mass standards are given on the right.

(fourth lane, right arrow), suggesting that the lower form may be cell cycle regulated. Additional proteins of higher molecular masses were identified by $R 1$ in both the immunoprecipitation lane (second lane) and the SDS cell lysate lanes (third and fourth lanes), but the identities of these proteins are currently unknown.

Phosphopeptide mapping of MKK labeled in vivo. In continuing our efforts to identify the in vivo phosphorylation sites of MKK1, both ${ }^{32} \mathrm{P}$-labeled phosphoproteins identified above were eluted separately from the polyacrylamide gel, digested with thermolysin, and subjected to HVE/TLC (Fig. 8). Two phosphopeptides that were identified for the lower phosphoprotein (Fig. 8A, labeled $\gamma$ and $\delta$ ) did not comigrate with the p34 ${ }^{c d c 2}$-phosphorylated thermolysin-treated synthetic peptide (Fig. 8B, labeled 1). Three thermolysin-generated phos-

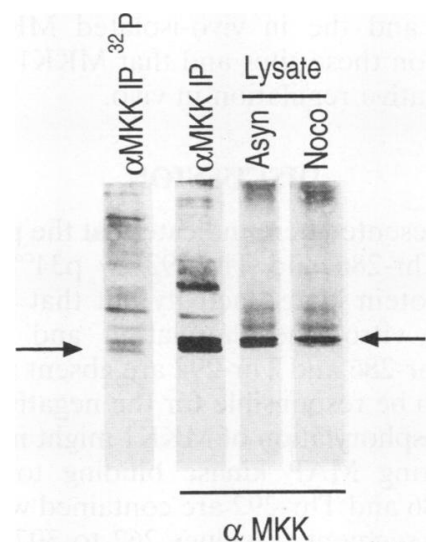

FIG. 7. Identification of MKK in asynchronously growing (Asyn) and nocodazole-blocked (Noco) HeLa cells. Lanes: first, direct exposure of the immunoprecipitate (IP) from ${ }^{32} \mathrm{P}$-labeled HeLa cells in the second lane to film; second, MKK doublet immunoprecipitated and then immunoblotted with the MKK1 antibody (R1); third, MKK doublet identified in an SDS cell lysate from asynchronously growing HeLa cells; fourth, nocodazole-blocked HeLa cell lysate. The first and second lanes were subjected to electrophoresis separately from the third and fourth lanes. 


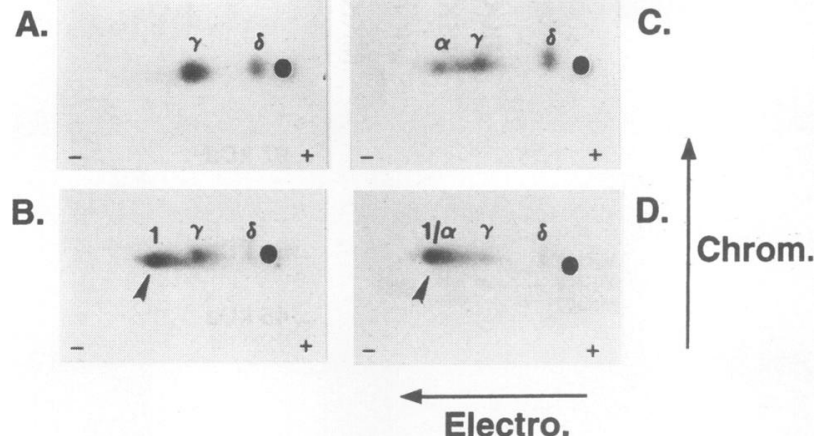

FIG. 8. HeLa cell MKK phosphopeptide maps. (A) Lower MKK phosphoprotein. (B) Lower MKK phosphoprotein mixed with synthetic MKK phosphopeptide. (C) Upper MKK phosphoprotein. (D) Upper MKK phosphoprotein mixed with synthetic MKK phosphopeptide. The migration of the synthetic phosphopeptide is marked by an arrowhead in panels B and D. The electrophoretic (Electro.) and chromatography (Chrom.) dimensions are labeled by arrows. origin. Panels $\mathrm{A}$ and $\mathrm{C}$ were exposed with an intensifying screen at $-70^{\circ} \mathrm{C}$ for $15 \mathrm{~h}$. Panels B and D were exposed for $7.5 \mathrm{~h}$ to minimize exposure background.

phopeptides were identified for the upper phosphoprotein (Fig. 8C, labeled $\alpha, \gamma$, and $\delta$ ); the $\alpha$ phosphopeptide comigrated with the phosphorylated MKK1 peptide (Fig. 8D, labeled $1 / \alpha)$. These data suggest that the lower MKK phosphoprotein does not contain the $\mathrm{p} 34^{c d c 2}$ phosphorylation site(s) or that the site(s) is not phosphorylated but that the upper MKK phosphoprotein does contain the site(s) phosphorylated in vivo. Furthermore, the similarity of the phosphopeptide maps of the upper and lower phosphoproteins (Fig. 8A versus $8 \mathrm{C}$ ) suggest that these proteins are closely related or possibly identical.

In summary, p34 $4^{c d c 2}$-phosphorylated recombinant MKK1 and ${ }^{32} \mathrm{P}$-labeled MKK isolated from asynchronous HeLa cells both contain a thermolysin-generated phosphopeptide that comigrates in two-dimensional thin-layer chromatography with a synthetic MKK1 peptide phosphorylated by $\mathrm{p} 34^{c d c 2}$ on Thr-286 and Thr-292. This result suggests that the recombinant MKK1 protein and the in vivo-isolated MKK protein are phosphorylated on these sites and that MKK1 may be subject to the same negative regulation in vivo.

\section{DISCUSSION}

The results presented here indicate that the phosphorylation of MKK1 on Thr-286 and Thr-292 by p34 $4^{c d c 2}$ in vitro will inhibit MKK protein kinase activity but that $\mathrm{p} 34^{c d c 2}$ will not catalyze the in vitro phosphorylation and inactivation of MKK2. Since Thr-286 and Thr-292 are absent in MKK2, these sites are likely to be responsible for the negative regulation of MKK1. The phosphorylation of MKK1 might inactivate kinase activity by altering MAP kinase binding to the molecule. Residues Thr-286 and Thr-292 are contained within an unusually proline-rich segment (residues 262 to 307 ) containing 11 prolines out of 45 residues $(1,9,38,45)$. A comparison of the MKK1 amino acid sequence with the amino acid sequence and structure of cyclic AMP-dependent protein kinase shows that the residues between MKK1 domains IX and X form a loop structure just below the enzymatic cleft (21). This region of MKK is much larger than those of other protein kinases; 10 or 11 residues are typical of many protein kinases (18), but MKK contains 49 residues in this region. This feature might impart the unique specificity of MKK for both $\mathrm{p} 42^{\text {mapk }}$ and $\mathrm{p} 44^{\text {mapk }}$, and phosphorylation might alter this enzyme-substrate interaction. Since MKK1 and MKK2 do not share significant homology in this region (13 of 32 residues are shared) and only MKK1 contains the $\mathrm{p} 34^{c d c 2}$ phosphorylation sites, MKK1 and MKK2 are likely to be regulated differently in vivo.

These findings are important to MKK1 regulation and to the regulation of the entire $42^{\text {mapk }}$ cascade because they imply that a negative feedback mechanism controls MKK1 activity. The $\mathrm{p} 34^{\text {cdc2 }}$-catalyzed phosphorylation of MKK1 in vitro overrides the activating phosphorylation that can be accomplished by Raf $(10,20,23)$. Since HeLa cell MKK1 is phosphorylated on the same threonine residues whose phosphorylation is catalyzed by $\mathrm{p} 34^{c d c 2}$ kinase in vitro and this phosphorylation causes the enzymatic inactivation of MKK1, MKK1 could be negatively regulated by these phosphorylations in vivo as well. Furthermore, there exists in asynchronous HeLa cells a form of MKK that is not phosphorylated on the inactivation site(s). Given the specificity of the R1 antibody for MKK1, this protein probably represents the active MKK1 form.

Does $\mathrm{p} 34^{c d c 2}$ kinase catalyze the phosphorylation and inactivation of MKK1 in vivo? It is of interest to speculate that the inactivating MKK1 phosphorylation(s) may only occur during the cell cycle when $\mathrm{p} 34^{\text {cdc }}$ kinase is most active to prevent an untimely activation of the MKK/MAP kinase pathway. Our data support this hypothesis by demonstrating that the upper MKK1 phosphoprotein, which contains the inactivation sites phosphorylated, predominates during $\mathrm{M}$ phase, when $\mathrm{p} 34^{c d c 2}$ is most active. Furthermore, M phase-blocked HeLa cells do not contain active MKK and $\mathrm{p} 42^{\text {mapk }}$ (data not shown). In support of this idea, Tamemoto et al. failed to identify active MAP kinase in nocodazole-treated $\mathrm{CHO}$ cells or in $\mathrm{M}$-phase $\mathrm{CHO}$ cells prepared by mechanically shaking the M-phase cells off the culture plate (42). On the basis of these observations, we propose that during mitosis, threonine 286 and threonine 292 serve to inhibit MKK1 activity and suppress the MAP kinase pathway.

The protein kinase responsible for the in vivo phosphorylation of MKK1 remains to be demonstrated unequivocally. However, the phosphorylation of MKK1 by mitotic p34 ${ }^{c d c 2}$ kinase in vitro suggests that during $M$ phase, this enzyme could be responsible for the corresponding in vivo phosphorylations identified in HeLa cell MKK. During the start of M phase, the physical barriers blocking an interaction between these protein kinases is eliminated once the nuclear envelope breaks down. Therefore, a direct association of $\mathrm{p} 34^{c d c 2}$ kinase and MKK1 would be possible at this point in the cell division cycle. Although the data presented here suggest that mitotic $\mathrm{p} 34^{c d c 2}$ kinase could be responsible for the in vivo phosphorylation during $M$ phase, we currently do not know what the phosphorylation state of MKK1 is during $G_{1} / S, S$, or $G_{2}$ of the cell division cycle.

During the $G_{0} / G_{1}$ transition, the position of the cell cycle at which MKK and $\mathrm{p} 42^{\text {mapk }}$ become transiently activated, $\mathrm{p} 34^{c d c 2}$ kinase is not active and possibly not capable of a direct interaction with MKK because of localization differences. These limitations suggest that the inactivating MKK phosphorylation(s) may not occur or may be carried out by a p34 ${ }^{c d c 2}$. related kinase active in $G_{1}$. Although Thr-292 represents an ideal MAP kinase phosphorylation site (6), p42 $2^{\text {mapk }}$ can probably be ruled out as a potential negative feedback regulator of MKK1 during $G_{0} / G_{1}$ because of a poor MKK1 phosphorylation $K_{m}$ and weak inhibitory effects upon MKK1 (data not shown). Further experiments are also necessary to address all of these issues more thoroughly.

Several observations suggest that $\mathrm{p} 42^{\text {mapk }}$ regulation is com- 
plex and varies, depending upon the cell system and activating agent. Injection of active p34 $4^{c d c 2}(16)$ or cyclins (26) into Xenopus oocytes results in sustained $\mathrm{p} 42^{\text {mapk }}$ activity, which rapidly decreases upon fertilization, suggesting that $\mathrm{p} 34^{c d c 2}$ acts upstream of $\mathrm{p} 42^{m a p k}$. However, injection of cyclins into clam oocytes fails to activate $\mathrm{p} 42^{\text {mapk }}$ but does cause $\mathrm{p} 34^{\text {cdc2 }}$ activation (40). These observations suggest that $\mathrm{p} 42^{\text {mapk }}$ proteins from Xenopus and clam oocytes are not functional homologs and/or that they are regulated differently. Therefore, multiple MKK-related enzymes may differentially regulate p42mapk activity, depending upon the cell type and/or activating agent. Supporting this hypothesis, MKK clones which lack Thr-286 and Thr-292 have been isolated from a rat cDNA library (44), and cloned Xenopus oocyte MKK does not contain these phosphorylation sites (22). Thus, p42 mapk feedback mechanisms acting through MKK may depend upon the MKK isoforms present in the stimulated cell.

The demonstration in this report that MKK1 can be phosphorylated and inactivated in vitro by $\mathrm{p} 34^{c d c 2}$ and the identification of the same MKK phosphorylations in vivo provide evidence that $\mathrm{p} 34^{c d c 2}$ kinase could modulate the activity of extracellular signal-regulated protein kinases. Existing paradigms of growth factor action strive to describe the mechanisms by which these external signals stimulate cell division. Our data expand this paradigm by suggesting that cell division negatively affects the growth factor-activated protein kinase cascade.

\section{ACKNOWLEDGMENTS}

We thank G. L. Russo, R. Del Vecchio, and M. J. Weber for helpful suggestions and $M$. Vandenberg for purifying $\mathrm{p} 34^{c d c 2}$ kinase. We are grateful to G. Binns and N. Poppito for excellent technical assistance in protein chemistry. We thank J. Wu for providing the rat MKK1 and MKK2 DNA clones and S. Pelech for providing the STE7 antibody.

This work was supported by National Institutes of Health grant AG 10208 (to D.R.M.) and by American Cancer Society grants BE69D (to T.W.S.) and CB71499 (to D.R.M.). Funding was also provided by the Greenwall Foundation and the Sara Chait Memorial Foundation (to D.R.M.). A.J.R. was a Cold Spring Harbor Laboratory Association Fellow and is supported by an NIH fellowship (GM15924).

\section{REFERENCES}

1. Ashworth, A., S. Nakielny, P. Cohen, and C. Marshall. 1992. The amino acid sequence of a mammalian MAP kinase kinase. Oncogene 7:2555-2556.

2. Brizuela, L., G. Draetta, and D. Beach. 1989. Activation of human $\mathrm{CDC} 2$ protein as a histone $\mathrm{H} 1$ kinase is associated with complex formation with the p62 subunit. Proc. Natl. Acad. Sci. USA 86:4362-4366.

3. Burgering, B. M. T., G. J. Pronk, P. C. van Weeren, P. Chardin, and J. L. Bos. 1993. cAMP antagonizes p $21^{\text {ras }}$-directed activation of extracellular signal-regulated kinase 2 and phosphorylation of mSos nucleotide exchange factor. EMBO J. 12:4211-4220.

4. Charles, C. H., H. Sun, L. F. Lau, and N. K. Tonks. 1993. The growth factor-inducible immediate-early gene $3 \mathrm{CH} 134$ encodes a protein-tyrosine-phosphatase. Proc. Natl. Acad. Sci. USA 90: 5292-5296.

5. Clarke, P. R., and E. Karsenti. 1991. Regulation of $\mathrm{p} 34^{c d c 2}$ protein kinase: new insights into protein phosphorylation and the cell cycle. J. Cell Sci. 100:409-414.

6. Clark-Lewis, I., J. S. Sanghera, and S. L. Pelech. 1991. Definition of a consensus sequence for peptide substrate recognition by $\mathrm{p} 44^{m p k}$, the meiosis-activated myelin basic protein kinase. J. Biol. Chem. 266:15180-15184.

7. Cobb, C. H., T. G. Boulton, and D. J. Robbins. 1991. Extracellular signal-regulated kinases: ERKs in progress. Cell Regul. 2:965-978.

8. Cook, S. J., and F. McCormick. 1993. Inhibition by cAMP of ras-dependent activation of raf. Science 262:1069-1072.

9. Crews, C. M., A. Alessandrini, and R. L. Erikson. 1992. The primary structure of MEK, a protein kinase that phosphorylates the ERK gene product. Science 258:478-480.

10. Dent, P., W. Haser, T. A. J. Haystead, L. A. Vincent, T. M. Roberts, and T. W. Sturgill. 1992. Activation of mitogen-activated protein kinase kinase by v-Raf in NIH 3 T3 cells and in vitro. Science 257:1404-1407.

11. Draetta, G., and D. Beach. 1988. Activation of cdc2 protein kinase during mitosis in human cells: cell cycle-dependent phosphorylation and subunit rearrangement. Cell 54:17-26.

12. Erickson, A., D. M. Payne, P. A. Martino, A. J. Rossomando, J. Shabanowitz, M. J. Weber, D. F. Hunt, and T. W. Sturgill. 1990. Identification by mass spectrometry of threonine 97 in bovine myelin basic protein as a specific phosphorylation site for mitogenactivated protein kinase. J. Biol. Chem. 265:19728-19735.

13. Errede, B., A. Gartner, Z. Zhou, K. Nasmyth, and G. Ammerer. 1993. MAP kinase-related FUS3 from S. cerevisiae is activated by STE7 in vitro. Nature (London) 362:261-264.

14. Gautier, J., M. J. Solomon, R. N. Booher, J. F. Bazan, and M. W. Kirschner. 1991. cdc25 is a specific tyrosine phosphatase that directly activates p34 $4^{c d c 2}$. Cell 67:197-211.

15. Gomez, N., and P. Cohen. 1991. Dissection of the protein kinase cascade by which nerve growth factor activates MAP kinases. Nature (London) 353:170-173.

16. Gotoh, Y., K. Moriyama, S. Matsuda, E. Okumura, T. Kishimoto, H. Kawasaki, K. Suzuki, and E. Nishida. 1991. Xenopus M phase MAP kinase: isolation of its cDNA and activation by MPF. EMBO J. 10:2661-2668.

17. Graves, L. M., K. E. Bornfeld, E. W. Raines, B. C. Potts, S. G. MacDonald, R. Ross, and E. G. Krebs. 1993. Protein kinase A antagonizes platelet-derived growth factor-induced signaling by mitogen-activated protein kinase in human arterial smooth muscle cells. Proc. Natl. Acad. Sci. USA 90:10300-10304.

18. Hanks, S., and A. Quinn. 1991. Protein kinase catalytic domain sequence database: identification of conserved features of primary structure and classification of family members. Methods Enzymol. 200:38-62.

19. Haystead, C. M. M., J. Wu, P. Gregory, T. W. Sturgill, and T. A. J. Haystead. 1993. Functional expression of a MAP kinase in COS cells and recognition by an ant-STE7/byr1 antibody. FEBS Lett. 317:12-16.

20. Howe, L. R., S. J. Leevers, N. Gomez, S. Nakielny, P. Cohen, and C. J. Marshall. 1992. Activation of the MAP kinase pathway by the protein kinase raf. Cell 71:335-342.

21. Knighton, D. R., J. Zheng, L. F. T. Eyck, V. A. Ashford, N.-H. Xuong, S. S. Taylor, and J. M. Sowadski. 1991. Crystal structure of the catalytic subunit of cyclic adenosine monophosphate-dependent protein kinase. Science 253:407-414.

22. Kosaka, H., E. Nishida, and Y. Gotoh. 1993. cDNA cloning of MAP kinase kinase reveals kinase cascade pathways in yeasts to vertebrates. EMBO J. 12:787-794.

23. Kyriakis, J. M., H. App, X. F. Zhang, P. Banerjee, D. L. Brautigan, U. R. Rapp, and J. Avruch. 1992. Raf-1 activates MAP kinasekinase. Nature (London) 358:417-421.

24. Laemmli, U. K. 1970. Cleavage of structural proteins during the assembly of the head of bacteriophage T4. Nature (London) 227:680-685.

25. L'Allemain, G., J.-H. Her, J. Wu, T. W. Sturgill, and M. J. Weber. 1992. Growth factor-induced activation of a kinase activity which causes regulatory phosphorylation of $\mathrm{p} 42 /$ microtubule-associated protein kinase. Mol. Cell. Biol. 12:2222-2229.

26. Luca, F. C., E. K. Shibuya, C. D. Dohrmann, and J. V. Ruderman. 1991. Both cyclin $A \Delta 60$ and $B \Delta 97$ are stable and arrest cells in M-phase, but only cyclin B $\Delta 97$ turns on cyclin destruction. EMBO J. 10:4311-4320.

27. Marshak, D. M., M. T. Vandenberg, Y. S. Bae, and I. J. Yu. 1991. Characterization of synthetic peptide substrates for $\mathrm{p} 34^{c d c 2}$ protein kinase. J. Cell. Biochem. 45:391-400.

28. Moreno, S., and P. Nurse. 1990. Substrates for $\mathrm{p} 34^{\text {cdc2 }}$ : in vivo veritas? Cell 61:549-551.

29. Nakielny, S., P. Cohen, J. Wu, and T. W. Sturgill. 1992. MAP kinase activator from insulin-stimulated skeletal muscle is a protein threonine/tyrosine kinase. EMBO J. 11:2123-2129.

30. Norbury, C., and P. Nurse. 1992. Animal cell cycles and their 
control. Annu. Rev. Biochem. 61:441-470.

31. Otsu, M., Y. Terada, and H. Okayama. 1993. Isolation of two members of the rat MAP kinase kinase gene family. FEBS Lett. 320:246-250.

32. Payne, D. M., A. J. Rossomando, P. Martino, A. K. Erickson, J. H. Her, J. Shabanowitz, D. F. Hunt, M. J. Weber, and T. W. Sturgill. 1991. Identification of the regulatory phosphorylation sites in pp42/mitogen-activated protein kinase (MAP kinase). EMBO J. 10:885-892.

33. Pelech, S. L., and J. S. Sanghera. 1992. Mitogen-activated protein kinases: versatile transducers for cell signaling. Trends Biochem. Sci. 17:233-238.

34. Rossomando, A., J. Wu, M. J. Weber, and T. W. Sturgill. 1992. The phorbol ester-dependent activator of the mitogen-activated protein kinase $\mathrm{p} 42^{\text {mapk }}$ is a kinase with specificity for the threonine and tyrosine regulatory sites. Proc. Natl. Acad. Sci. USA 89:52215225.

35. Russo, G. L., M. T. Vandenberg, I. J. Yu, Y.-S. Bae, B. R. Franza, Jr., and D. R. Marshak. 1992. Casein kinase II phosphorylates p3 $34^{c d c 2}$ kinase in G1 phase of the HeLa cell division cycle. J. Biol. Chem. 267:20317-20325.

36. Seger, R., N. G. Ahn, T. G. Boulton, G. D. Yancopoulos, N. Panayotatos, E. Radziejewska, L. Ericsson, R. L. Bratlien, M. H. Cobb, and E. G. Krebs. 1991. Microtubule-associated protein 2 kinases, ERK1 and ERK2, undergo autophosphorylation on both tyrosine and threonine residues: implications for their mechanism of activation. Proc. Natl. Acad. Sci. USA 88:6142-6146.

37. Seger, R., N. G. Ahn, J. Posada, E. S. Munar, A. M. Jensen, J. A. Cooper, M. H. Cobb, and E. G. Krebs. 1992. Purification and characterization of mitogen-activated protein kinase activator(s) from epidermal growth factor-stimulated A431 cells. J. Biol. Chem. 267:14373-14381.

38. Seger, R., D. Seger, F. J. Lozeman, N. G. Ahn, L. M. Graves, J. S. Campbell, L. Ericsson, M. Harrylock, A. M. Jensen, and E. G. Krebs. 1992. Human T-cell mitogen-activated protein kinase kinases are related to yeast signal transduction kinases. J. Biol. Chem. 267:25628-25631.

39. Sevetson, B. R., X. Kong, and J. C. Lawrence, Jr. 1993. Increasing cAMP attenuates activation of mitogen-activated protein kinase. Proc. Natl. Acad. Sci. USA 90:10305-10309.

40. Shibuya, E. K., A. J. Polverino, E. Chang, M. Wigler, and J. V. Ruderman. 1992. Oncogenic ras triggers the activation of $42-\mathrm{kDa}$ mitogen-activated protein kinase in extracts of quiescent Xenopus oocytes. Proc. Natl. Acad. Sci. USA 89:9831-9835.

41. Sturgill, T. W., and J. Wu. 1991. Recent progress in characterization of protein kinase cascades for phosphorylation of ribosomal protein S6. Biochim. Biophys. Acta 1092:350-357.

42. Tamemoto, H., T. Kadowaki, K. Tobe, K. Ueki, T. Izumi, Y. Chatani, M. Kohno, M. Kasuga, Y. Yazaki, and Y. Akanuma. 1992. Biphasic activation of two mitogen-activated protein kinases during the cell cycle in mammalian cells. J. Biol. Chem. 267:2029320297.

43. Wu, J., P. Dent, T. Jelenik, A. Wolfman, M. J. Weber, and T. W. Sturgill. 1993. Inhibition of the EGF-activated MAP kinase signaling pathway by adenosine $3^{\prime}, 5^{\prime}$-monophosphate. Science 262:1065-1069.

44. Wu, J., J. K. Harrison, P. Dent, K. R. Lynch, M. J. Weber, and T. W. Sturgill. 1993. Identification and characterization of a new mammalian mitogen-activated protein kinase kinase, MKK2. Mol. Cell. Biol. 13:4539-4548.

45. Wu, J., J. K. Harrison, L. A. Vincent, C. Haystead, T. A. J. Haystead, H. Michel, D. F. Hunt, K. R. Lynch, and T. W. Sturgill. 1993. Molecular structure of a protein-tyrosine/threonine kinase activating p42 mitogen-activated protein (MAP) kinase: MAP kinase kinase. Proc. Natl. Acad. Sci. USA 90:173-177.

46. Wu, J., A. J. Rossomando, J. H. Her, R. Del Vecchio, M. J. Weber, and T. W. Sturgill. 1991. Autophosphorylation in vitro of recombinant 42-kilodalton mitogen-activated protein kinase on tyrosine. Proc. Natl. Acad. Sci. USA 88:9508-9512. 